\title{
Levantamento das anomalias dentárias de número (supranumerários) em radiografias panorâmicas de um serviço de documentação odontológica da cidade do Salvador -Bahia
}

A survey of dental anomalies (supranumeraries) using panoramic radiographies in a center of dentistry documentation in Salvador-city-Bahia

Andrea de Castro Dayube ${ }^{1}$, Larissa Pompermayer ${ }^{2}$, Nilson Pena Neto Segundo ${ }^{3}$

${ }^{1}$ Especialista em radiologia odontológica e imaginologia pela Faculdade de Odontologia da UFBA; ${ }^{2}$ Especialista em radiologia odontológica e imaginologia pela USP-Bauru; ${ }^{3}$ Doutor em radiologia pela faculdade de odontologia de Piracicaba (UNICAMP).

\begin{abstract}
Resumo
O presente trabalho teve como objetivo analisar dados epidemiológicos de dentes supranumerários diagnosticados por meio de radiografias panorâmicas. Foram avaliadas 1475 radiografias panorâmicas e verificada a prevalência de gênero, idade do paciente, relação de acometimento maxila-mandíbula e localização dos supranumerários. Constatou-se a prevalência de dentes supranumerários em aproximadamente 3,7\% da amostra, com maior ocorrência no gênero feminino, predominância na região de pré-molares inferiores, seguida da região de molares superiores e da região de pré-maxila. Pôde-se inferir, com os resultados obtidos, que a ocorrência de dentes supranumerários representa uma anormalidade relativamente incomum, com predominância na maxila.
\end{abstract}

Palavras-chave: Dente Supranumerário. Radiografia panorâmica. Anormalidades Dentárias.

\begin{abstract}
OBJECTIVE-This study aimed to analyze epidemiological data of supernumerary teeth diagnosed by panoramic radiographs. MATERIAIS AND METHODS-In the present study 1475 panoramic radiographs were examined and examined the prevalence of gender, patient age, relationship involvement jaws and location of supernumeraries. RESULTS- It's found the prevalence of supernumerary teeth in approximately $3.7 \%$ of the sample, with higher incidence in females, predominantly in the region of lower pre-molars, followed by the upper molars and anterior upper jaw. CONCLUSIONS -The occurrence of supernumerary teeth is a relatively uncommon abnormality, predominantly in the upper jaw.

Keywords: Supranumerary tooth. Panoramic radiography .
\end{abstract}

\section{INTRODUÇÃO}

Hiperdontia, como o próprio nome sugere, é o desenvolvimento de um maior número de dentes, e os dentes adicionais

são chamados de supranumerários. Morfologicamente, os supranumerários podem ser classificados em conoides,

tuberculados, suplementares e odontoma. Os conoides são mais comumente encontrados na dentição permanente e manifestam-se como mesiodente; os tuberculados são frequentemente descritos como em "forma de barril" e podem ser encontrados invaginados; os suplementares referem-se a uma duplicação dos dentes de uma arcada normal, sendo mais comumente duplicado o incisivo lateral superior permanente, embora possam ocorrer molares e pré-molares suplementares (NORONHA, 2004).

Recebido em 12 de março de 2010; revisado em 16 de janeiro de 2011. Correspondência / Correspondence: Andréa Dayube. Rua Engenheiro Celso Torres, 18, apto 202- Graça . CEP: 40150 -280. Salvador. Bahia. Brasil. Tel: (71) 3331-4302.E-mail: deadayube@hotmail.com
Segundo o mesmo autor, a etiologia dos extranumerários ainda não está completamente elucidada, existindo várias teorias que tentam explicar a presença dessa anomalia de desenvolvimento. Uma das teorias mais aceitas é o da hiperatividade da lâmina dental.

De acordo com Castilho e colaboradores (1997), o desenvolvimento dos dentes é um processo contínuo, no qual o crescimento fisiológico e os estágios morfológicos variáveis, juntos, resultam na forma e na estrutura dental final. Os processos fisiológicos envolvidos no desenvolvimento dentário são: iniciação, proliferação, histodiferenciação, morfodiferenciação, aposição e calcificação. A fase de iniciação representa o início da formação da lâmina dental; portanto, quaisquer interferências ocorridas nesse estágio podem resultar em únicos ou vários dentes supranumerários (hiperdontia).

Além da teoria da hiperatividade da lâmina dental Tommasi (1989 apud FERNANDES et al., 2005) cita ainda as seguintes teorias: teoria atávica, que se constitui na 
regressão a padrões primitivos do Homo sapiens; associação a distúrbios do desenvolvimento, como as fissuras lábio-palatinas, a síndrome de Gardner, a Disostose Cleidocraniana; teoria da dicotomia do botão dental, que consiste na divisão de um germe dental em dois germes iguais; e, ainda, a teoria da hereditariedade.

Segundo Freitas (1992), é grande a ocorrência de supranumerários nos casos de fendas palatinas e na Disostose Cleidocraniana.

Entretanto, Blanco Ballesteros (2005) pôde também observar, através da avaliação clínica e de radiografias oclusal, lateral e panorâmica, a presença de múltiplos dentes supranumerários em um paciente do sexo masculino, não-sindrômico, causando severa maloclusão.

Gallas e García (2000) destacaram a influência do fator genético no desenvolvimento de dentes supranumerários. Eles relataram um caso em que duas irmãs apresentaram dois dentes supranumerários entre os incisivos centrais, provocando a retenção dos incisivos permanentes.

Quanto ao número e o local de aparecimento de dentes supranumerários, existe uma considerável variedade. Eles são mais encontrados na dentição permanente e menos comuns na dentição decídua, e, quando nela ocorrem, podem frequentemente se localizar na região de pré-maxila (FARIA, 2003).

Conforme Brunner e Guedes Pinto (1983), os dentes supranumerários aparecem na dentição decídua em cerca de $0,5 \%$ das crianças, mais frequentemente nos meninos, localizados na região anterior da maxila.

Ainda conforme Brunner e Guedes Pinto (1983), os dentes natais e neonatais também podem ser considerados como estruturas calcificadas supranumerárias quando, pelo exame radiográfico, for determinada a presença dos dentes incisivos decíduos ainda intraósseos.

De acordo com a localização ou período de irrupção, os dentes supranumerários podem ser denominados, como: mesiodens ou mesiodentes, quando localizados na linha da maxila ou pré-maxila; distomolares, se situados posteriormente aos terceiros molares; paramolares, quando erupcionados por vestibular ou lingual dos molares, ou até mesmo interproximalmente; pré-decíduos, estruturas córneas que se apresentam sobre os rebordos alveolares ao nascimento (CAMPOS et al., 2006).

Estudos das anomalias dentárias de número têm apresentado resultados nem sempre convergentes.

Para Barros e Barreto (2007), o mesiodens é o dente supranumerário mais comum e está localizado na região anterossuperior. Sua forma mais encontrada é a conoide de raiz curta e, na maioria dos casos, achase impactado, podendo ser encontrada mais de uma unidade. A prevalência maior é para o gênero masculino sobre o feminino e, nas dentições, a prevalência é maior para a mista e (ou) permanente sobre a decídua.
Conforme a experiência clínica de muitos odontólogos, o supranumerário, se não for removido, pode trazer alguns efeitos deletérios para o paciente, como reabsorção radicular do dente vizinho, maloclusão, formação de cistos, erupção ectópica, retardo, impacção ou má formação do dente permanente, diastema, entre outros, determinando assim a importância de um diagnóstico precoce e do tratamento adequado.

Segundo Primo, Wilhelm e Bastos (1997), a ocorrência dessa anomalia pode estar também associada com problemas estéticos e maloclusões.Ainda de acordo com esses autores, existe uma série de fatores que podem influenciar o desenvolvimento de uma oclusão normal, o seu alinhamento e relação com o elemento antagonista. A maioria desses distúrbios ocorre na dentição mista, e a presença de anomalias dentárias, como a de dentes supranumerários, pode interferir na oclusão.

Em estudos de Castilho e colaboradores (2000), pôde-se constatar que o atraso na irrupção e impacção dentária são mais comuns quando da presença desses elementos dentários supranumerários.

Stuani e colaboradores (1999) destacam a importância de se recomendar uma radiografia panorâmica aos seis anos, idade na qual a maioria das anomalias dentárias é diagnosticada, prevenindo, dessa forma, a instalação de maloclusões.

Freitas (1992) também ressalta a importância do exame radiográfico no diagnóstico, prognóstico, plano de tratamento e preservação nas especialidades odontológicas.

Radiografias periapicais, oclusais e panorâmicas são recomendáveis na rotina da clínica, principalmente em pacientes que apresentam distúrbios de número e posicionamento dental (COSTA; NUNES; FACCO, 2003).

A radiografia panorâmica tem como peculiaridade apresentar, por meio de uma projeção única, numa só imagem, muitas estruturas anatômicas. Além disso, possui uma série de outras vantagens, como produção de imagens anatômicas praticamente sem distorções, dose de radiação significativamente menor para o paciente, simplicidade e rapidez no procedimento, sobreposição reduzida das estruturas anatômicas, procedimentos mínimos no controle de infecção. Por essas vantagens, a radiografia panorâmica é considerada como exame de escolha na detecção de anomalias dentárias de desenvolvimento (LANGLAND; LANGLAIS, 2002; WHITE; PHAROAH, 2004).

Devido à importância do exame radiográfico na detecção e prevenção de transtornos na oclusão e até mesmo no aparecimento de patologias, o presente trabalho teve como objetivo avaliar, através de um banco de dados, laudos de radiografias panorâmicas, com o objetivo de investigar a presença de dentes supranumerários, analisando sua forma, localização, quantidade e presença quanto a sexo e idade. 


\section{MATERIAL E MÉTODOS}

Foram avaliados, através de um banco de dados de um serviço privado de documentação odontológica da cidade do Salvador (BA), 1475 laudos de radiografias panorâmicas de todos os pacientes que frequentaram a clínica para a realização desse exame, no período compreendido entre abril a agosto de 2007, sem qualquer limitação em relação a idade e gênero.

Naqueles laudos radiográficos em que se constatou a presença de dentes supranumerários, eles foram selecionados e classificadas de acordo com quantidade, idade, gênero e localização. Com relação à localização, foi avaliada a relação entre maxila e mandíbula, e a região, dividida em região de molares, pré-molares e caninos - incisivos.

Os dados obtidos foram submetidos a uma análise estatística. Por tratar-se de amostra nãoprobabilística, foram calculadas as estatísticas descritivas pertinentes à natureza das variáveis do estudo, sendo que foram obtidas as frequências absolutas e relativas de dentes supranumerários de acordo com as regiões em função dos indivíduos e do total de dentes supranumerários existentes, gerando, consequentemente, uma medida de prevalência e uma proporção, respectivamente. A análise foi efetuada no pacote estatístico livre R versão 2.6 .2 (2008).

\section{RESULTADOS E DISCUSSÃO}

Dos 1475 laudos de radiografias panorâmicas analisados, pôde-se observar um total de 55 indivíduos que apresentavam dentes supranumerários, existindo a presença de mais de um dente supranumerário em alguns indivíduos, calculando-se um total de 72 dentes. A prevalência aproximada foi de $3.7 \%$.

Esses dados corroboram os estudos de Cecchi (2003), que, ao avaliar 995 radiografias panorâmicas, pôde encontrar um resultado de 48 dentes supranumerários em 35 pacientes, com índice de prevalência de 3,52\%.

Na literatura estudada, a prevalência de dentes supranumerários varia de 0,1 a 3,8\%, em estudos realizados em diferentes populações.

Primo, Whilhelm e Bastos (1997), encontraram uma prevalência de supranumerários de $2.96 \%$ na população estudada. Nos estudos de Faria (2003) pôdese observar uma prevalência de $2.4 \%$ de dentes supranumerários. Outros autores como: Watanabe e colaboradores (1997); Lee e colaboradores (2005); Severo (1992) puderam observar uma prevalência de supranumerários de $0,45 \%, 1,1 \%, \mathrm{e} 1,7 \%$ respectivamente.

Da amostra total de 1475 laudos radiográficos analisados, 565 pacientes eram do sexo masculino e 910 do sexo feminino (Tabela 1); 55 indivíduos apresentaram a anomalia de número estudada, sendo 31 do gênero feminino $(56,36 \%)$ e 24 , do gênero masculino $(43,64 \%)$.

\begin{tabular}{ccc} 
Tabela 1 - Informações Gerais & \\
\hline SEXO & NÚMERO & $\%$ \\
\hline MASCULINO & 565 & 38,3 \\
FEMININO & 910 & 61,70 \\
DENTES & & \\
SUPRANUMERÁRIOS & 55 & 3,7 \\
\hline
\end{tabular}

Nota::1- Idade Minima (5); 2- Idade Máxima(95); 3Média(24,7); Desvio padrão(11,2).

Nos estudos de Watanabe e colaboradores (1997), as mulheres apresentaram uma incidência $40 \%$ maior de dentes supranumerários em relação aos homens.

Alguns autores não destacam predominância significativa de dentes extranumerários em relação ao sexo. Severo (1992), ao avaliar arquivos de 2880 laudos panorâmicos de pacientes de uma clínica privada em Recife, pôde observar a presença de 51 pacientes que apresentavam dentes supranumerários, sendo 26 do sexo masculino (51\%) e 25 do sexo feminino (49\%).

Entretanto, muitos autores descrevem uma predominância masculina sobre a feminina numa proporção de 2:1 (CECCHI, 2003; CASTILHO et al. 2000; WATANABE et al. 1997).

Quanto à distribuição por faixa etária a terceira década apresentou maior prevalência de dentes supranumerários, fato que pode ser explicado por existir uma proporção de $45 \%$ dos indivíduos, na população estudada, pertencentes a essa faixa etária. A idade mínima dessa população foi de 5 anos e máxima de 95 anos.

Com relação à distribuição topográfica, analisando-se a proporção de acordo com a região, observou-se que a região de pré-molares inferiores foi a mais afetada (31\%), seguida pela região de molares superiores (29\%). Entretanto, considerando-se o estudo da prevalência, a região de molares superiores foi a mais afetada, seguida da região de pré-molares inferiores (Gráfico 1) (Tabela 2).

Alguns estudos descrevem a região de pré-maxila como a de maior prevalência dos dentes supranumerários (CECCHI, 2003; CASTILHO et al., 2000; WATANABE et al., 1997).

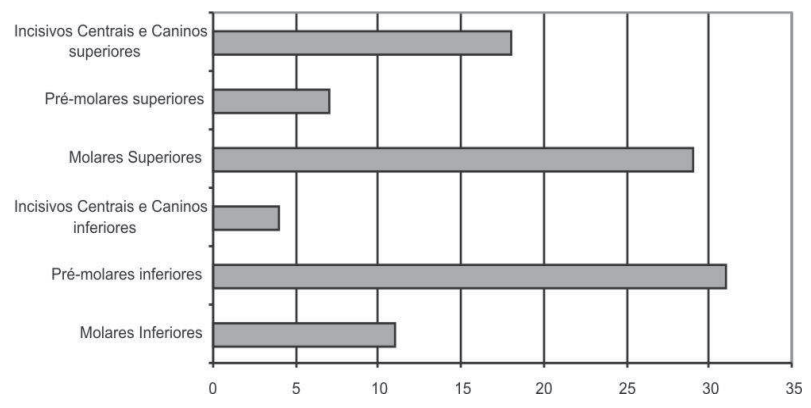

Gráfico 1- Proporção de dentes supranumerários de acordo com a região $(n=72)$ 
Tabela 2 - Prevalência de dentes supranumerários de acordo com a região

\begin{tabular}{ccc}
\hline REGIÃO & $\mathrm{N}$ & PREVALÊNCIA \\
\hline 1 & 13 & $0,9 \%$ \\
2 & 4 & $0,27 \%$ \\
3 & 18 & $1,22 \%$ \\
4 & 3 & $0,2 \%$ \\
5 & 14 & $0,95 \%$ \\
6 & 7 & $0,47 \%$ \\
\hline
\end{tabular}

Nota: 1-Incisivos centrais e caninos superiores; 2-Pré-molares superiores; 3-Molares superiores; 4-Incisivos centrais e caninos inferiores; 5-Pré-molares inferiores; 6-Molares inferiores

Analisando-se a relação entre maxila e mandíbula, notou-se uma proporção de aproximadamente $59 \%$ de dentes supranumerários na maxila contra $41 \%$ na mandíbula. Esses resultados confluem com os achados de Severo e colaboradores (1992), que encontraram um percentual de $62 \%$ na maxila e $38 \%$ na mandíbula. Cecchi (2003) encontrou resultado parecido, uma predileção pela maxila de $64,58 \%$, em relação à mandíbula, de 35,42\%.

Outros estudos apontam para um percentual mais acentuado de ocorrência de hiperdontia na maxila. Watanabe e colaboradores (1997) observaram que a região maxilar apresentou $73 \%$ dos achados, enquanto a região mandibular apenas $27 \%$.

No que concerne à quantidade de supranumerários encontrada, verificou-se que, dos 55 pacientes que apresentaram dentes extranumerários no presente estudo, 78\% tinham apenas um dente em excesso, $16 \%$ dois e $6 \%$ múltiplos. Esses dados corroboram os achados de Primo, Wilhelm e Bastos (1997), que constataram a presença de $80,36 \%$ de casos simples (apenas um dente em excesso), 16,08\% de duplos e 3,56\% de múltiplos (três ou quatro dentes em excesso); corroboram ainda os de Watanabe e colaboradores (1997), que encontraram um resultado de $67 \%$ dos pacientes da população estudada apresentando apenas um dente em excesso. (Tabela 3 ).

Foi possível observar também, na população estudada, que $50 \%$ dos pacientes que apresentaram dentes supranumerários na região de pré-molares inferiores os apresentaram bilateralmente, fato não relatado em outros estudos.

\section{CONSIDERAÇÕES FINAIS}

De acordo com os resultados obtidos através da análise dos achados das radiografias panorâmicas, pode-se concluir que:

- Na amostra total, constituída por 1475 laudos de radiografias panorâmicas, observou-se uma prevalência de 3,7\%.

- Na amostra total, observou-se a presença de 55 pacientes com dentes supranumerários.
Tabela 3 - Prevalência e proporção de dentes supranumerários de acordo com a quantidade

\begin{tabular}{ccccc}
\hline $\begin{array}{c}\text { Quantidade de dentes } \\
\text { supranumerários por } \\
\text { paciente }\end{array}$ & $\begin{array}{c}\text { Número de } \\
\text { pacientes }\end{array}$ & $\begin{array}{c}\text { Dentes } \\
\text { supranumerários } \\
\text { (prevalência) }\end{array}$ & $\begin{array}{c}\text { Quantidade de } \\
\text { dentes } \\
\text { supranumerários }\end{array}$ & $\begin{array}{c}\text { Dentes } \\
\text { supranumerários } \\
\text { (proporção) }\end{array}$ \\
\hline 01 & 43 & $78,18 \%$ & 43 & $60 \%$ \\
02 & 9 & $16,36 \%$ & 18 & $25 \%$ \\
03 & 01 & $1,82 \%$ & 03 & $4 \%$ \\
04 & 02 & $3,64 \%$ & 08 & $11 \%$ \\
Mais de04 & - & - & - & $0,00 \%$ \\
Total & 55 & $100 \%$ & 72 & $100 \%$ \\
\hline
\end{tabular}

- Dos 55 pacientes, 31 eram do gênero feminino (56,36\%) e 24 eram do gênero masculino (46,64\%).

Quanto à distribuição por faixa etária, a terceira década apresentou maior prevalência de dentes supranumerários.

Analisando-se a relação entre maxila e mandíbula, verificou-se uma proporção de aproximadamente $59 \%$ de dentes supranumerários na maxila contra $41 \%$ na mandíbula.

Com relação à distribuição topográfica observou-se que a região de pré-molares inferiores foi a mais afetada (31\%), seguida pela região de molares superiores $(29 \%)$.

\section{REFERÊNCIAS}

BARROS, R. S.; BARRETO, C. Mesiodens: revisão de literatura. Disponível em:<http://www.odontologia.com>. Acesso em: 4 abr. 2007

BLANCO BALLESTEROS, G. Dientes multiples supernumerarios no relacionados a um síndrome: Reporte de un caso. R. Estomat., Calí, v.13, n.1, p.13-19, 2005

BRUNNER, V.; GUEDES PINTO, A. C. Anomalias do desenvolvimento dental e sua importância na prática clínica. R. Assoc. Paul. Cir. Dent., São Paulo, v.37, n.2, mar./abr. 1983.

CAMPOS, P. S. F. et al. Anomalias Dentárias de Desenvolvimento. In: PANELLA, Jurandyr (Ed.). Radiologia Odontológica e Imaginologia. Rio de Janeiro: Guanabara Koogan, 2006. cap. 13, p. 201-202.

CASTILHO, J. B. et al. Dentes supranumerários: revisão de literatura. RFO UFP., Passo Fundo, v. 2, n. 2, p. 19-24, jul./dez. 1997.

CASTILHO, J. B. et al. Estudo sobre a prevalência de dentes supranumerários numa população infantil na faixa etária de 6 a 12 anos com vistas à prevenção de futuras maloclusões. R. Paul. odontol., São Paulo, v. 22, n. 1, jan./fev. 2000.

CECCHI, P. Prevalência de anomalias dentárias de desenvolvimento através de radiografias panorâmicas para documentação ortodôntica de pacientes na faixa etária de 8 a 20 anos na cidade do Rio de Janeiro. 2003. Dissertação (Mestrado) Faculdade de Medicina, Universidade do Rio de Janeiro, 2003.

COSTA, S.; NUNES, E.; FACCO, E. Distomolares. R. Fac. Odontol. Lins, Lins, SP, v. 15, n. 1, p. 33-36, 2003.

FARIA, P. J. V. Prevalência das anomalias dentárias observadas em crianças de 5 a 12 anos de idade no município de Belém: um estudo radiográfico. 2003. Dissertação (Mestrado) - Faculdade de Odontologia, Universidade de São Paulo, São Paulo, 2003.

FERNANDES, A. V. et al. Quarto molar incluso: relato de caso. R. Cir. Traumatol. Buco-Maxilo-Fac., Recife, v. 5, n.2, p.61-66, abr./ jun. 2005.

FREITAS, L. Radiologia bucal: técnicas e interpretação. São Paulo: Pancast, 1992 . cap. 13 , p. $203-226$ 
GALLAS, M. M.; GARCIA, A. Retention of permanent incisors by mesiodens: a family affair. Br. Dent. J., London, v. 188, n. 2, p. 6364, Jan. 2000

LANGLAND, O.; LANGLAIS, R. Imagem em Odontologia. São Paulo: Santos, 2002, cap. 9, p.207-208.

LEE, K. B. et al. Estudo da prevalência de anomalias dentárias de desenvolvimento, através de radiografias panorâmicas, numa amostra populacional da cidade de São Paulo: parte II. RPG Rev. Pos-Grad., v. 12, n. 1, p. 85-93, jan./mar. 2005.

NORONHA, V. (Ed.). Dentes Supranumerários. 2004. Disponível em: <http://www.boasaude.com>. Acesso em: 13 nov. 2009.

PRIMO, L.; WILHELM, R.; BASTOS, E. Frequência e características dos dentes supranumerários em crianças brasileiras: consequências e tratamentos propostos. R. Odontol. Univ. São Paulo, São Paulo, v. 11, n. 4, out./dez. 1997.
SEVERO, A. M. R. Levantamento das anomalias dentárias (anodontia e supranumerários) em radiografias panorâmicas de um serviço de documentação odontológica da cidade do Recife-Pernambuco. 1992. Dissertação (Mestrado) - Faculdade de Odontologia de Pernambuco, Fundação Universidade de Pernambuco, Camurujibe, 1992.

STUANI, A. et al. As complicações do diagnóstico tardio do mesiodens: revista de literatura e relato de caso clínico. R. Fac. Odontol. Univ. Fed. Bahia, Salvador, v. 18, jul./dez. 1999.

WATANABE, P. et al. Estudo radiográfico (Ortopantomográfico) da incidência das anomalias dentais de número na região de Piracicaba - S.P. ROBRAC: R. Odontol. Bras. Central, Goiania, v. 6, n. 21, 1997.

WHITE, S. C.; PHAROAH, M. J. Oral radiology: principles and Interpretation. Filadelfia: Mosby, 2004, cap. 10, p. 191 